\title{
Funding open access journal publishing Article processing charges
}

$\mathbf{T}$ he widely accepted definition of open access (OA), as coined by scholar and advocate Peter Suber, is that it is scholarly literature that is "digital, online, free of charge, and free of most copyright and licensing restrictions." 1 To clarify, OA literature is free of charge to the reader, and there are two primary outlets that authors can use to deliver free literature to readers. Authors can reserve in their publication agreements the right to post their manuscripts in an OA repository (commonly referred to as "Green OA") or they can publish their works in an OA journal (commonly referred to as "Gold OA.") While the cost of the former method of access is free for authors, with the costs of maintaining the repositories absorbed by the host institutions by using existing technological infrastructure and staff, the latter method of delivering OA content still comes at a cost for the publishers. That cost, however, is often passed on to authors rather than the traditional method of recouping costs through paid subscriptions.

Although the Directory of Open Access Journals reports that nearly two-thirds of OA journals listed there do not charge authors, ${ }^{2}$ a recent study indicates that $50 \%$ of OA articles have been published after the author paid a fee. ${ }^{3}$ OA has been experiencing a tremendous growth, as evidenced by the increasing number of journals publishing wholly OA or offering it on an article-level basis, more institutions adopting OA policies, and a mandate from the White House's Office for Science and Technology Policy requiring federal agencies - as is already mandated for the National Institutes of Health-to make federally funded research available for public consumption. Accordingly, more authors will be exploring OA publishing opportunities and possibly paying a fee to do so when opting to publish in an OA journal.

Libraries traditionally have served readers of scholarly literature by covering the cost of publishing through paid subscriptions. In order to support faculty authors who opt to publish in OA journals that charge their authors, it is crucial for librarians to be aware of the various funding models being employed by OA journals.

An established business model adopted by OA publishers is assessing authors an article processing charge (APC). Often, authors can rely upon research grants to cover APCs in order to comply with the grant requirements or as part of the implicit cost of research. Authors without grants, or with grants but no

Christine Fruin is scholarly communications librarian at University of Florida, e-mail: christine.ross@ufl.edu Fred Rascoe is scholarly communications librarian at Georgia Institute of Technology, e-mail: fred.rascoe@library.gatech.edu

Contact series editors Zach Coble, digital scholarship specialist at New York University, and Adrian Ho, director of digital scholarship at the University of Kentucky Libraries, atcrlnscholcomm@gmail.com with article ideas

(C) 2014 Christine Fruin and Fred Rascoe, published under Creative Commons CC-BY 4.0 license, http://creativecommons.org/licenses/by/4.0/ 
reserved funding, may look to their university for assistance. Universities administering funds for OA publishing must grapple with several questions about management and distribution of these funds. For publishers not relying upon APCs to fund their operations, business model experiments abound, such as the PeerJ author membership model and the SCOAP3 consortium model. The challenge for librarians is to not only educate themselves about these available business models and the pros and cons of each but also how to use that knowledge to meaningfully impact the field of scholarly communication.

\section{Article processing charges}

With the expansion of a governmental mandate requiring public access to federally funded research, ${ }^{4}$ an increase in the number of institutions mandating their employees to make their works available in an OA repository, and the evidence that the number of articles being published in OA journals charging APCs is growing, ${ }^{5}$ authors will increasingly be faced with the dilemma of how to cover the cost of publishing their work in OA journals that charge APCs. APCs range from \$200 to $\$ 5,000$, with $\$ 904$ reported as the average in the United States. ${ }^{6}$ Senior researchers and faculty may be able to cover this cost by writing the fees into their grants. However, APCs can be overwhelming for graduate students or junior faculty without grant funding. To respond to this need, many institutions have established OA publishing funds as a means of covering some or all of the APC cost incurred by their faculty, staff, and students.

There are a variety of issues institutions must confront when establishing OA publishing funds. First, what will be the source of funds? Libraries may elect to repurpose a portion of their collections budgets for funding the payment of APCs. Libraries may also have access to discretionary funds within their budgets. However, because these monies are frequently non-recurring, use of discretionary funds may be advised only in a pilot project so as to allow libraries to gauge usage and need and help make a case for more permanent funding.
Another possible source for institutional OA funds is the institution's research division. As the division charged with tracking and managing grant funding, it has a vested interest in helping researchers and faculty not only meet public access requirements but also ensure coverage of publishing research in OA journals. At some campuses, individual colleges or departments also contribute monies to institutional OA funds. Finally, monies occasionally come from a central institutional account or operating budget that is administered by a provost or another senior administrator.

Institutions secondly need to consider what types of OA publishing will be supported. Will "hybrid journals," which are publications in journals that charge subscriptions but allow individual articles to be OA for a fee, be supported? Some institutions have elected to support hybrid publishing at a reduced rate while others have chosen not to support it at all. Additionally, institutions should consider whether to apply any criteria of journal quality in determining eligibility. Will only journals listed in the $D i$ rectory of Open Access Journals ${ }^{7}$ be eligible for funding or will there be a narrower class of eligible journals, such as only those not included on Jeffrey Beall's List of Predatory Publishers? ${ }^{8}$

A third issue that institutions need to consider is who will be eligible for funding. This requires not only determining what institutionally affiliated persons will be eligible for support but also whether unaffiliated coauthors will be eligible for support. Institutions may elect to prorate publishing fund awards based upon the number of affiliated authors. That is, if there are three authors on a paper, and only two of them are affiliated with the funding university, then funding reimbursement is two-thirds of the maximum allotment. A final issue that institutions may want to consider is whether to impose award caps on a per-article and per-author basis. Imposing caps is a means to maximize the number of articles and authors that benefit from the funds. 
Institutions may also elect to assist with APCs by purchasing an institutional membership with OA publishers. Several major OA publishers discount their APCs if an author is affiliated with an institution that has a membership. Below is a chart with examples of publishers offering APC discounts to authors at member institutions: sciences. Review of submissions and publication decisions are conducted independent of the business of the sponsoring funding agencies. Instead, independent academic reviewers provide these services. While elife publication funds are currently covered by the funding agencies, the journal may implement APCs as part of a broader sustainability plan in the future. ${ }^{10}$

\begin{tabular}{|c|c|c|}
\hline Publisher & $\begin{array}{l}\text { Membership } \\
\text { Fee }\end{array}$ & Discount \\
\hline BioMed Central & $\begin{array}{l}\text { Based on number of } \\
\text { researchers and gradu- } \\
\text { ate students at institu- } \\
\text { tion }\end{array}$ & $\begin{array}{l}15 \% \text { on APC for affili- } \\
\text { ated authors }\end{array}$ \\
\hline Hindawi & $\begin{array}{l}\text { Flat rate calculated ac- } \\
\text { cording to the research } \\
\text { output level of the in- } \\
\text { stitute and its historical } \\
\text { publishing pattern in } \\
\text { Hindawi journals }\end{array}$ & $\begin{array}{l}\text { APC waived for affili- } \\
\text { ated authors during } \\
\text { period of institutional } \\
\text { membership }\end{array}$ \\
\hline Royal Society Publishing & Flat annual fee & $\begin{array}{l}25 \% \text { on APC for affili- } \\
\text { ated authors }\end{array}$ \\
\hline Springer Open Access & $\begin{array}{l}\text { Flat annual fee based } \\
\text { on number of science } \\
\text { and medical research- } \\
\text { ers and graduate stu- } \\
\text { dents at institution }\end{array}$ & $\begin{array}{l}15 \% \text { on APC for affili- } \\
\text { ated authors }\end{array}$ \\
\hline
\end{tabular}

\section{Emerging models for funding $O A$ publishing}

Charging authors APCs is not the only business model employed by OA publishers. In recent years, some new models have emerged for generating income to cover the costs of producing a journal. The journal elife is an example of funding agencies moving beyond support of existing journals and setting up their own OA publication. In 2011, three major research funders, the Howard Hughes Medical Institute (United States), the Max Planck Society (Germany), and the Wellcome Trust (United Kingdom), announced that they would begin publication of an OA journal featuring high-impact and peer-reviewed research in life and biomedical
Some publishers are altering the standard APC business model in various ways while still maintaining quality and sustainability. One example of an altered model is the "author membership" model, perhaps most prominently exemplified by the new journal Peer.${ }^{11}$ Under the "author membership" model, the author pays a fee to be a member of the journal, and that fee gives the member publishing privileges. In the case of PeerJ, there are levels of membership that allow for one, two, or unlimited publications per year, depending on the level of membership that is paid. Under this model, the fee for membership is lower than many APCs, and, once paid, there is no further monetary cost 
to publish. The only further obligation on the author is to commit to commenting on or peer reviewing the submissions of other authors.

Another possible model is the consortial membership within a discipline. The most successful and well-known of this model is the SCOAP $3^{12}$ consortium in which most of the major journals in a specific field (in this case, high-energy physics) participate in OA publishing. Under the terms of the SCOAP3 consortium agreement, the participating journals agreed to begin publishing all articles OA, and, in turn, all of the subscription costs are prorated for consortial members. The authors bear no cost of the funding.

F1000 is a publishing company that will publish submissions immediately for open peer review and revisioning. The online publication F1000 Research requires submitters to pay an APC for publication, but for those who are members of F1000 or are participating peer referees, a heavily discounted APC is charged upon publication. The incentive to cash-strapped authors, then, is to participate in a community hosted by a publishing entity in exchange for a reduced charge for OA publication. ${ }^{13}$

Recently, the American Chemical Society (ACS) introduced a model ${ }^{14}$ for OA whereby authors who publish articles in traditional tollaccess ACS titles receive credits for a future article to be published OA at no cost. This is a transitional strategy for ACS as they move toward their own OA model for doing business.

\section{Conclusion}

Libraries are viewed as the primary resource at academic institutions for information on scholarly publishing issues, including OA. Faculty interest in OA publishing is increasing, and when recent federal mandates for OA are implemented, the interest from those doing federally funded research will grow quickly. As such, librarians should be prepared to answer questions from faculty and researchers on how they can cover the costs that are often attendant to publishing in OA journals. While librarians should advocate and educate their constituents on the availability of green
OA and the cost-free options available with many gold OA journals, they should also be cognizant of the frequency at which faculty and researchers are publishing in gold OA publications that charge a fee and the available options for covering those costs.

\section{Notes}

1. Peter Suber, Open Access (Cambridge: MIT Press, 2012), 4.

2. Directory of Open Access Journals, accessed January 14, 2014, www.doaj.org.

3. David J. Solomon and Bo-Christer Björk, "A Study of Open Access Journals Using Article Processing Charges," Journal of the American Society of Information Sciences (2012): 63, 1485-1495, accessed January 14, 2014, doi:10.1002/asi.22673.

4. U.S. Office of Science and Technology Policy, Memorandum for the Heads of Executive Departments and Agencies: Increasing Access to Federally Funded Scientific Research, February 22, 2013, www.whitehouse.gov/sites/default/files/microsites/ostp /ostp_public_access_memo_2013.pdf.

5. Solomon and Björk, "Study of Open Access Journals," 1493.

6. Ibid., 1492.

7. "Directory of Open Access Journals."

8. "Scholarly Open Access," accessed February 27, 2014, http://scholarlyoa.com /publishers/. See also http://scholarlyoa.com /individual-journals/.

9. elife, accessed February 27, 2014, http://www.elifesciences.org/

10. "Frequently Asked Questions," eLife, accessed February 27, 2014, http://www. elifesciences.org/about/frequently-askedquestions/\#7.

11. peerJ, accessed February 27, 2014, http://www.peerj.org.

12. "SCOAP3," accessed February 27, 2014, http://scoap3.org.

13. "F1000 Research: Referee Incentives," accessed March 17, 2014, http://f1000research.com/referee-incentives

14. "ACS Author Rewards", accessed March 18, 2014, http://acsopenaccess.org /acs-author-rewards/. n 